\title{
Distributed gatekeeping. Uncovering the patterns of linking behaviors on Facebook
}

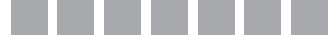 \\ Wojciech Walczak \\ Michat Meina \\ Krzysztof Olechnicki
}

NICOLAUS COPERIICUS UNIVERSITY, POLAND

DOI: 10.19195/1899-5101.10.1(18).2

\begin{abstract}
Based on an analysis of 770,269 links posted by 1,969 Polish Facebook users, the present article investigates how the users' characteristics influence their link-sharing behaviors, and how these characteristics are related to social rewards received for posting links. Male users, older ones and inhabitants of larger cities tend to link more to politics-related news (they also receive more social feedback for doing that) while female users, younger ones and inhabitants of smaller locations tend to link more to entertainment-related sites. The cluster analysis of linking strategies of Facebook users suggests that the most common behavior is to provide a mixture of news and entertainment-related links, although pure "news-keeper" and "entertainment-keeper" types of users are distinguishable.
\end{abstract}

KEYWORDS: gatekeeping, social networking sites, sharing links, Facebook, computer-mediated communication.

\section{INTRODUCTION}

In the context of media systems the practice of gatekeeping concerns individuals who hold the power to decide which piece of information to publish or broadcast to the mass audience. The gatekeeping power of these individuals lies mostly in their position in the organizational structure, or the ownership structure of the media company. The earliest approaches to gatekeeping considered the media routine as a basic factor influencing gatekeeping decisions. Subsequent models suggested a number of levels on which the gatekeeping process should be considered: ideological, extramedia, organizational, media routines and individual (Shoemaker \& Reese, 1996).

With the advent of the Internet, a new class of gatekeepers emerged, namely, the web search engines such as Google Web Search (Diaz, 2008; Rogers, 2009). These new actors imposed an additional layer of filtering and derived their power from 
providing easier access to the vast amounts of media content. The informationpush news model evolved into the individualized information-pull approach (Webster \& Ksiazek, 2012). Yet another step was the introduction of content aggregation websites built upon Web2.0 technologies. Based on this shift, Bruns suggested that the idea of gatekeeping loses its relevance in the new media ecosystem because news dissemination is being mediated by the gatewatchers - various Web sites whose primary activity is to point their audience to a selected number of articles produced by the traditional news media (Bruns, 2003).

The ongoing technological and social transformation that has resulted from these profound changes is now being accompanied by a rise of a new class of content curators: distributed gatekeepers - the countless users of Social Networking Sites (SNSs; see: Ellison \& Boyd, 2007) who connect their social capital and technological tools to filter, spread and discuss the news. Their impact on the social perception of events ranges from small circles of closest friends to hundreds or thousands of Facebook (abbreviated: FB) "friends" and subscribers (Bernstein et al., 2013).

Holbert et al. anticipated that "social networking tools and recommendation systems could create an unprecedented opportunity for large groups of individuals to play a role in the filtering of political messages" (2010, p. 24), and thus turn from news consumers into agenda setters. The predicted change has been going on at the same time, and by the first half of 2012 Facebook finally came abreast with Google as one of the two most important sources of traffic to online publishers (Smith, 2012). The social phenomenon of sharing information proved not to be replaced by automated procedures of processing and retrieving information - only enhanced by them.

The concept of distributed gatekeeping itself was discussed before in the context of the political blogosphere's potential to become an alternative form of journalism. Schiffer defined the term as "story-placement choices made by a large number of readers" (2007). Here, this term was chosen to label the phenomenon of sharing links on FB for a number of reasons. The first element of the term stresses the reality of the fragmented media ecosystem. It also suggests that although individuals are scattered around the social network, their individual actions contribute to the emergent system of information dissemination on the Internet. The second element of the term stresses the relation between individuals and technological tools that empower them, just as the media institutions provide gatekeeping abilities to their employees. It also ties the traditional gatekeeping research, with its focus on many levels of possible influences on the filtering practices, to the social sharing of links.

The present research may be perceived as an important addition to the filter bubble studies, which tend to focus on how personalized news streams impact the knowledge and attitudes of the information receivers (Pariser, 2011). That branch of research suggests that individuals expose their preferences to the filtering algorithms, the algorithms then learn these preferences and, in effect, users end up isolated in an environment where conflicting viewpoints are underrepresented (Bozdag, 2015). This paper contributes to the filter bubble approach by focusing on link 
providers, and thus highlighting that the news space on Facebook is, at the beginning of the process, shaped by people who post links. As it turns out, the link posters themselves have certain social and usage characteristics, which may strongly affect what kind of links enter the FB news feeds in the first place. Neither the Facebook users who use the service as a news source nor the filtering algorithms choose information from the universe of all the news available. Thus, it is important to shed some light on people who pre-filter news before adding them to FB's info-sphere.

Based on an analysis of 770,269 links posted by 1,969 Polish Facebook users, the present article aims at investigating how the users' characteristics influence linksharing behaviors, and how these characteristics are related to social rewards received for posting links. This research overcomes a number of weaknesses of the previous studies: (1) it relies on actual FB data instead of self-reports on FB activity, (2) it is not limited to students as $82.7 \%$ of the individuals in the sample are 25 years old or older, and (3) it relies on a relatively large sample of FB users.

\section{SHARING INFORMATION ON FACEBOOK}

Facebook's statistics for 2010 offer a staggering measure: every 20 minutes one million links were shared on the site (Democracy UK, 2010). Based on the measure of the average number of links posted per day and a number of users' characteristics, this study explores:

RQ1. How do the characteristics of FB users affect the frequency of posting links?

Nadkarni \& Hofmann, in their review of the existing literature on the psychological factors contributing to FB use, concluded that it is motivated by two primary needs: (1) the need to belong and (2) the need for self-presentation (Nadkarni \& Hofmann, 2012). Baek et al.'s research examined motivations of 217 individuals for sharing links on FB and showed that posting links serves both of these needs (Baek et al., 2011). It is an act of self-presentation as posted links manifest the user's interests, taste and views, and it may also contribute to the individual's feeling of belonging once the social feedback (i.e. likes and comments) is received. Glynn et al. studied the factors that contribute to sharing links to news stories on FB. Based on a survey conducted on 1050 students, faculty members, and staff from a large Midwestern university they found out that women and younger respondents were more likely to use FB for news purposes (Glynn et al., 2012). Thus, the second and the third research questions are:

RQ2. Do the characteristics of FB users affect what types of links they post?

RQ3. What types of FB link posters could be distinguished?

A number of studies have considered the Uses \& Gratifications perspective in the context of the formation of news habits in the Internet environment (Ruggiero, 2000; Diddi \& LaRose, 2006). Recent studies on various SNSs highlight that gratifications such as enjoyment, retrieving and sharing information, socializing, and 
establishing status and reputation influence the patterns of social media usage (Dunne et al., 2010; Valenzuela et al., 2009). Lee and Ma studied the influence of gratification and experiential factors on students' intention to share the news on social media, and confirmed most of the previous findings. They found out that prior social media sharing experience, socializing, status seeking, as well as information seeking and collecting influenced the intention to engage in this kind of activity. They also found that entertainment was not a significant predictor for news sharing in social media (Lee \& Ma, 2012).

Based on an online survey of 1,026 multinational FB users, McAndrew and Jeong found out that age was a negative predictor of posting and looking at links. The number of friends was positively correlated with using links. Those not currently in a close relationship showed more intensive posting, sharing, and looking at links (McAndrew \& Jeong, 2012, p. 2363). In the context of social gratification of links sharing, the fourth and fifth research questions are:

RQ4. Do the characteristics of FB users affect the amount of feedback received per link?

RQ5. Do the characteristics of FB users affect the amount of feedback received per link depending on the link type?

Prior to this study only a couple of papers examined the exact links being shared on FB. Baresch et al. studied small portions of links (328 total) shared by 38 U.S. FB users (Baresch et al., 2011). Robertson et al. examined links posted on the official Facebook fan-pages of Barack Obama, Hillary Clinton and John McCain over the two years prior to the 2008 U.S. Presidential election (Robertson et al., 2009).

\section{METHOD}

\section{Data collection \& sampling}

The data was collected through a Facebook application designed to provide users with analytics about their and their friends' activities. Using the framework of FB, the application guaranteed that users control the access to their data through privacy settings and authorization procedures. The application used a wide range of anonymizing procedures, both in terms of the information provided by the users as well as in terms of the data provided by the Graph API (i.e., Graph API URLs and IDs of users and objects are either erased or encrypted).

The participants of this study provided a sample of 10,007 profiles. The data was then filtered to exclude (1) users who did not provide years of birth, (2) users who shared fewer than 50 links, (3) users whose feed was shorter than 100 entries, (4) users with number of friends smaller than 10, (5) users who did not provide gender information, (6) users who use FB in a language other than Polish, (7) users under 18 years of age. The filtering procedure aimed at omitting low-activity users as well as the users whose privacy settings could interfere with the results. As a result, as the sampling 
procedure was shaped to study people who post links on $\mathrm{FB}$, it has no representative value. Also, the initial data analysis led to the exclusion of 5 outliers who posted more than 20 links daily (with the two top outliers posting around 60 links daily). As a result, none of the users included in the analysis had been posting more than 15 links daily.

Therefore, a sample of 1,969 users emerged. The filtering rules affected the shape of the sample by increasing the number of males as compared to females (64.5\% of males in the filtered sample, compared to $54.7 \%$ of males in the unfiltered sample). This is due to the rule no. 2 as $58.4 \%$ of women in the full sample, compared to $43.8 \%$ of men, shared fewer than 50 links, and thus were excluded from the sample.

The time range of this study is dependent on individual histories of posting links. The minimum time delta between the first and the last link posted by a single user is 5 days, while the maximum is 1,910 days.

Table 1. Sample demographics

\begin{tabular}{|c|c|c|c|}
\hline Measure & Item & $\mathrm{N}$ & Percentage (\%) \\
\hline \multirow{2}{*}{ Gender } & Male & 1268 & 64.4 \\
\hline & Female & 701 & 35.6 \\
\hline \multirow{6}{*}{$\begin{array}{l}\text { Age } \\
\text { (years) }\end{array}$} & $18-24$ & 340 & 17.3 \\
\hline & $25-31$ & 858 & 43.6 \\
\hline & $32-38$ & 321 & 16.3 \\
\hline & $39-45$ & 182 & 9.2 \\
\hline & $46-52$ & 119 & 6.0 \\
\hline & $53+$ & 149 & 7.6 \\
\hline \multirow{8}{*}{$\begin{array}{l}\text { Location size } \\
\text { (number of inhabitants) }\end{array}$} & Countryside & 55 & 2.8 \\
\hline & Cities less than 100,000 & 255 & 13.0 \\
\hline & $100,000-199,999$ & 69 & 3.5 \\
\hline & $200,000-299,999$ & 416 & 21.1 \\
\hline & $300,000-399,999$ & 79 & 4.0 \\
\hline & $400,000-499,999$ & 45 & 2.3 \\
\hline & $500.000+$ & 473 & 24.0 \\
\hline & Unidentified & 577 & 29.3 \\
\hline
\end{tabular}

Note: $\mathrm{N}=1,969$.

Source: own elaboration.

\section{INDEPENDENT VARIABLES}

Age \& gender. Both age and gender of the users were obtained from the users' profile data. The age value was calculated by transforming the "birthday" variable. Users who did not provide either birthday or gender information were dropped from the study. 
Location size. The location size variable was created by matching the names of the locations as provided by the users with a list of Polish villages and cities ordered by number of inhabitants. Since not every user provided location data and not every location data provided was matched, an additional category "Unidentified" was added. The location information is considered reliable. In the collected data, the location update was observed mostly for users in their early- and mid-twenties, probably due to higher education-related migrations.

Number of friends. The number of friends was estimated based on friending reports (i.e., "X. is now friends with Y.") found in the users' feed streams. The obtained values, when compared to other statistics of the average number of FB friends, suggest that this measure is reliable.

Facebook skills. Based on a predefined list of $30 \mathrm{FB}$ activities (e.g. liking, commenting, sharing, creating an event, going to an event, clipping an offer, playing games, using apps, editing fields in the profile, inviting, rating, adding photos, subscribing, listing family members, recommending, etc.), the diversity of the users' activities was estimated. It is important to notice, though, that private messaging and chatting are not covered by this scale as these activities leave no trace in the gathered data.

Cultural competence. The "cultural competence" variable was estimated based on the users' fan-page likes. Each fan-page has a category assigned to it. Each user's fan-page likes were processed in order to assess how diverse they are. Thus, a user with 206 fan-page likes, each fan-page in a different category, would score the highest on the cultural competence scale, while a user with 1500 likes, all of them in a single category (be it Society \& culture website or Sport), would score the lowest on the cultural competence scale. Similar to FB skills scale, the cultural competence scale measures the diversity of the user's interests/skills, and not their intensity. While the idea of diversity of liked pages might be discussable there is a strong link between diversity and cultural competence as seen e.g. by social work and other social service agencies which use cultural diversity training in order to develop and enhance cultural competence.

\section{DEPENDENT VARIABLES}

Daily average number of links posted. Based on a number of links and the time difference between the oldest and the newest link posted, a daily average number of links posted was calculated.

Average feedback per link posted. Based on the number of comments and likes received under every posted link, the average feedback per link was counted (autolikes and auto-comments excluded).

Links categories. Every single domain name with 15 or more occurrences has been categorized using the following classification system: (1) Blogs - blogging platforms and personal blogs; (2) Commercial - auction websites, on-line stores, discount services, company websites, price-comparing services; (3) Culture - sites 
devoted to arts and culture in general; (4) Entertainment - image-based, useruploaded websites, celebrity news sites, TV stations, on-line gaming sites, fashion or vehicles-oriented sites; (5) FB.com - links for photos, fan-pages, posts, notes, groups, applications etc.; (6) Local - local news sites, radio stations, associations, on-line forums, and non-governmental organizations of local, national or international reach; (7) News - news sites, websites of political parties and political initiatives, websites promoting the political or economic ideas, government $\left({ }^{*}\right.$.gov) sites; (8) Religion - websites of religious orders, religious news websites, sanctuaries, religious associations, bookstores, and other initiatives; (9) Science - websites associated with science and education, science-oriented sites of internet portals, scholarly blogs, technology-related and gadgets-centered websites, computer forums and magazines; (10) SNSs - social networking sites other than Facebook, and social news websites; (11) Sports - sport news sites, websites of sport federations \& associations, teams and players, and fan websites; (12) Visual - video, photo and file hosting services; (13) Unexplained - URLs not covered by the classification scheme.

The frequencies of the domain names predefined in all of the above categories, as well as frequency of actually categorized links are presented in table 2 .

Table 2. Links statistics by category

\begin{tabular}{|r|l|r|r|r|}
\hline No & \multicolumn{1}{|c|}{ Category } & Number of predefined domains & Number of links & \multicolumn{1}{c|}{$\%$} \\
\hline 1 & Blogs & 132 & 39,030 & 5.07 \\
\hline 2 & Commercial & 119 & 6,374 & .83 \\
\hline 3 & Culture & 171 & 7,259 & .94 \\
\hline 4 & Entertainment & 281 & 51,289 & 6.66 \\
\hline 5 & FB.com & 6 & 166,541 & 21.62 \\
\hline 6 & News & 280 & 137,737 & 17.88 \\
\hline 7 & Local & 506 & 28,242 & 3.66 \\
\hline 9 & SNSs & 20 & 5,868 & .76 \\
\hline 10 & Science & 108 & 7,760 & 1.01 \\
\hline 11 & Sport & 92 & 4,845 & .63 \\
\hline 12 & Video & 94 & 7,443 & .97 \\
\hline 13 & Unexplained & 48 & 273,756 & 35.54 \\
\hline
\end{tabular}

Note: $\mathrm{N}=770,259$.

Source: own elaboration.

\section{RESULTS}

A total number of 770,259 links has been shared by 1,969 users under study. Most of the users $(1,868 ; 94.87 \%)$ posted no more than the average of two links daily. Out of the 
remaining 101 users, who on average posted more than two links daily, $66.3 \%$ were forty years old or older. A median for the daily average number of posted links equals 0.23 .

The distribution of the daily average number of links posted follows the power law distribution and approaches the $80 / 20$ rule (the Pareto principle) as 20\% of top users posted $65 \%$ of links. The heaviest linker posted 5,681 links during his 996 days of activity (5.7 links daily). These results confirm previous research on the participation divide: relatively few users engage in the distribution of content despite the widely available opportunities (Hargittai \& Walejko, 2008).

Table 3 presents intercorrelation coefficients between the independent variables (variables 1 to 6), as well as the correlation coefficients between the independent variables and the daily average number of links posted (variable 7), and between the independent variables and the fractions of links in respective categories (variables 8 to 20 ).

Table 3. Correlation matrix for user characteristics and types of links

\begin{tabular}{|c|c|c|c|c|c|c|c|}
\hline No & Item & $1 \dagger$ & $2 \dagger$ & $3 \ddagger$ & $4 \dagger$ & $5 \dagger$ & $6 \dagger$ \\
\hline 1 & Age & - & & & & & \\
\hline 2 & Gender & $-.245^{\star \star}$ & - & & & & \\
\hline 3 & Location size & $-.095^{\star *}$ & .041 & - & & & \\
\hline 4 & Number of friends & $.257^{\star \star}$ & $-.165^{\star *}$ & $.079^{\star *}$ & - & & \\
\hline 5 & Facebook skills & $-.126^{\star \star}$ & $-.059^{\star *}$ & $.132^{\star \star}$ & $.175^{\star \star}$ & - & \\
\hline 6 & Cultural competence & -.032 & -.027 & $.073^{\star \star}$ & $.094^{\star *}$ & $.319^{* *}$ & - \\
\hline 7 & Avg \# of links per day & $.314^{\star *}$ & $-.084^{\star *}$ & -.050 & .031 & $-.045^{\star}$ & $.220^{* *}$ \\
\hline 8 & Blogs & $.338^{\star *}$ & $-.129^{* *}$ & $.060^{*}$ & $.278^{\star \star}$ & -.025 & .028 \\
\hline 9 & Commercial & $-.068^{\star *}$ & .022 & $.091^{\star \star}$ & -.032 & .021 & -.001 \\
\hline 10 & Culture & .017 & .016 & $.151^{\star \star}$ & -.010 & $.069^{\star *}$ & $.054^{\star}$ \\
\hline 11 & Entertainment & $-.357^{\star *}$ & $.173^{\star *}$ & $-.116^{\star *}$ & $-.160^{\star \star}$ & -.028 & $-.139^{* *}$ \\
\hline 12 & FB.com & $.255^{\star *}$ & .042 & -.020 & .024 & $-.052^{\star}$ & .034 \\
\hline 13 & News & $.513^{\star *}$ & $-.234^{* *}$ & $.072^{\star \star}$ & $.237^{\star \star}$ & .004 & $.064^{\star *}$ \\
\hline 14 & Local & $.185^{\star \star}$ & $-.093^{\star *}$ & $.073^{\star *}$ & $.160^{\star *}$ & .017 & $.057^{\star}$ \\
\hline 15 & SNSs & $-.089^{\star \star}$ & $-.090^{* *}$ & .042 & -.033 & $.052^{*}$ & .031 \\
\hline 16 & Religion & $.161^{\star *}$ & -.044 & $-.056^{*}$ & $.069^{* *}$ & -.028 & .023 \\
\hline 17 & Science & .017 & $-.065^{\star \star}$ & $.095^{\star *}$ & .010 & $.045^{\star}$ & $.060^{* *}$ \\
\hline 18 & Sports & $-.066^{\star *}$ & $-.132^{\star \star}$ & -.011 & .000 & .016 & -.011 \\
\hline 19 & Visual & $-.424^{\star \star}$ & $.117^{\star \star}$ & .040 & $-.200^{\star \star}$ & .013 & -.039 \\
\hline 20 & Unexplained & $.091^{\star \star}$ & $-.085^{\star \star}$ & $.099^{* *}$ & $.093^{\star *}$ & $.096^{\star *}$ & $.080^{\star x}$ \\
\hline
\end{tabular}




\section{INTERCORRELATIONS FOR INDEPENDENT VARIABLES}

First of all, the intercorrelations between the key variables merit some discussion. A negative correlation between the age and gender variables indicates that the older the users, the fewer women there are in the sample $(\mathrm{r}=-.245, \mathrm{p}<.01)$. This is exactly the case. For example, among users aged $46+$ there are 220 males and 48 females.

Also, the older the users, the larger the number of friends $(\mathrm{r}=.257, \mathrm{p}<.01)$. A possible explanation would suggest that a few highly popular individuals among the older users elevate the correlation coefficient, but this is not the case: the median number of friends for the users aged $25-31$ is $278(\mathrm{~N}=858)$, while the median number of friends for the users aged $53+$ is $370(\mathrm{~N}=149)$.

There is also a positive correlation between the number of friends and the FB skills $(\mathrm{r}=.175, \mathrm{p}<.01)$, and the negative correlation between age and the FB skills $(\mathrm{r}=-.126, \mathrm{p}<.01)$. This is particularly interesting given the previous observation that the older the users, the larger the number of friends. Further investigation shows that with the growth of the number of friends the gap in the FB skills among the younger and older users widens. Thus, as the number of friends grows, the younger and older users vary in terms of how many features of the FB interface they employ. The younger users tend to diversify their usage of the service, while the older users tend to intensify the usage of the features they are familiar with.

\section{RQ1: The determinants of linking activity}

The daily average number of links posted correlated positively with age $(\mathrm{r}=.314$, $\mathrm{p}<.01)$ and cultural competence $(\mathrm{r}=.220, \mathrm{p}<.01)$. The correlation between gender and the daily average number of links posted was weak $(\mathrm{r}=-.084, \mathrm{p}<.01)$. These findings partly contradict some of the previous findings. Baek et al. found that the motivation for sharing links on FB is not associated with gender or age level (Baek et al., 2011, p. 2247). This study shows a moderate correlation between age and the amount of links shared (i.e., the older users share more links than the younger ones). The latter may be due to the differences in Facebook use among younger and older adults. A research by Brandtzæg et al. showed that the younger users tended to focus more on other features such as Facebook chat or mail (Brandtzæg et al., 2010, pp. 1022-1023).

\section{RQ2: Linking activity and types of links}

The Pearson's coefficients for age and the types of links indicate that the younger and older users differ in terms of the sources they link to. The older users link less often to Visual $(\mathrm{r}=-.424, \mathrm{p}<.01)$, and to Entertainment $(\mathrm{r}=-.357, \mathrm{p}<.01)$, and instead they link more often to News $(\mathrm{r}=.513, \mathrm{p}<.01), \operatorname{Blogs}(\mathrm{r}=.338, \mathrm{p}<.01)$, and Local $(\mathrm{r}=.185, \mathrm{p}<.01)$. These differences might be interpreted in two ways: either as a split between the textual media (older users), and the visual media (younger users), or as a split between the entertainment media (younger users), and the news 
media (older users). The above findings correspond to the previous findings. A study carried out in Norway showed that older adults, more often than younger users, participate in user-generated content sites in order to express themselves politically (Karahasanović et al., 2009, p. 663).

The analysis of the links posted within the FB.com category suggests that the split is rather between the news and the entertainment media that between the textual and the visual media. The links within the FB.com category consist mostly of photos shared from various fan-pages ( $91 \%$ of links pointed either to a single photo or an album of photos). Still, the older users post more links of this category $(\mathrm{r}=.255, \mathrm{p}<.01)$, and there is no effect for gender ( $\mathrm{r}=.042$, N.S.). A closer examination of the most frequently shared links shows that these links are mostly of the non-entertainment kind (among the top 10 most shared photos 8 were of a political nature).

A similar, although weaker, pattern of linking behaviors holds for the gender variable. Women more often link to Entertainment $(\mathrm{r}=.173, \mathrm{p}<.01)$, and to Visual $(\mathrm{r}=.117, \mathrm{p}<.01)$, and less often to News $(\mathrm{r}=-.234, \mathrm{p}<.01)$, and Blogs $(\mathrm{r}=-.129$, $\mathrm{p}<.01)$. These findings are particularly interesting in the light of Glynn et al.'s observations that young users and women are more likely to receive some or all of their news from SNSs (Glynn et al., 2012). This suggests that, at least in terms of disseminating news stories, there are age and gender divides with men and older users being the gatekeepers, and women and younger users being the audience.

In their examination of blogging, photo, and video-sharing behaviors online, Stefanone and Lackaff found that younger users, particularly female, post more photographs online. They referred to the connotations that the female image is maintained in Western culture, and concluded that young females are following broader cultural prescripts about image use (Stefanone \& Lackaff, 2009, p. 981). The present research suggests that this is also the case for Facebook, as both Entertainment and Visual encompass mostly image-based services.

The correlations between the location size and Culture $\left(\mathrm{r}_{\mathrm{s}}=.151, \mathrm{p}<.01\right)$ as well as the location size and Entertainment $\left(\mathrm{r}_{\mathrm{s}}=-.116, \mathrm{p}<.01\right)$ indicate that with the growth of the number of inhabitants, users link slightly more often to Culture and slightly less often to Entertainment sites. This finding suggests the importance of the geographical whereabouts of the users on their online activity. Given that the inhabitants of larger cities have better and wider access to cultural institutions, they are predestined to link to this kind of website. On the other hand, the inhabitants of smaller cities and the countryside are filling the void with generally accessible, location-unrelated entertainment sites.

The number of friends correlated positively with posting links to $B \operatorname{logs}(\mathrm{r}=.278$, $\mathrm{p}<.01)$, News $(\mathrm{r}=.237, \mathrm{p}<.01)$, and Local $(\mathrm{r}=.160, \mathrm{p}<.01)$, but negatively with Entertainment $(\mathrm{r}=-.160, \mathrm{p}<.01)$ and Visual $(\mathrm{r}=-.200, \mathrm{p}<.01)$. This may suggest that linkers to Blogs, News, and Local tend to accumulate larger audiences to proliferate their messages wider (goal-oriented linking; see: Rubin, 1984). 
At the same time, such users may be more likely to receive friend requests as the interest in politics and current affairs may indicate a higher social status. The negative correlations for Entertainment and Visual might be explained through the users' age. Older people have more friends $(\mathrm{r}=.257, \mathrm{p}<.01)$, and they tend to post more often to Blogs and News than to Entertainment and Visual Web sites.

The FB skills variable does not seem to impact the types of links posted (none of the observed statistically significant coefficients are larger than 0.1). The cultural competence showed the strongest negative correlation with Entertainment $(\mathrm{r}=-.139, \mathrm{p}=<.01)$. This suggests that cultural competencies impact strategy of linking behavior. More culturally competent users tend to link more than less culturally competent ones $(\mathrm{r}=.220, \mathrm{p}<.01)$, and they tend to diversify in terms of types of links they link to.

\section{RQ3: Facebook gatekeeper types}

We employed the automatic user profiling method to discover and examine the typical linking behavior of FB users. The linking similarity of two users is measured by Spearman's Rank Correlation coefficient $\rho\left(\mathrm{x}_{\mathrm{i}}, \mathrm{x}_{\mathrm{j}}\right)$, where $\mathrm{x}_{\mathrm{k}}$ is a vector composed of proportions of posted links in each category of k-th user. K-means cluster analysis was performed to estimate clusters of similar users, i.e., subsets of users that linking behavior is more similar within groups to each other than those in other groups. We discovered four unbalanced clusters with a low number of outliers $(<1 \%)$ depicted in Figure 1.

These four clusters represent four types of users: Entertainment-keepers ("C1"), Info-minimalists ("C2"), News-keepers ("C3") and Eclectics ("C4"). Entertainment-keepers are the least numerous of these four types (261 users, 13.25\%), but they are responsible for introducing new entertainment-related content into Facebook. Compared to the three remaining clusters, these users are the heaviest Entertainment and Visual link posters. On the other hand, they do not engage much into the reposting activity (see: FB.com category). They are entertainment providers, entirely indifferent to spreading political news.

It is important to notice, though, that three categories - Blogs, FB.com and Visual - are actually only labels for channels of communication. Every kind of information can be passed through these channels. Nevertheless, it is assumed that the user who is primarily interested in posting Entertainment links will be using these channels mostly for gatekeeping entertainment content. Simultaneously, it is assumed that the user who is primarily interested in posting News links will be using these channels to spread politics-related links.

Info-minimalists ("C2") differ from the Entertainment-keepers in two ways: they show minimal interest in gatekeeping politics-related links, and they more often engage in spreading links already existent in FB's ecosystem than providing new links (the usage proportions of FB.com and Entertainment categories are reversed between these two clusters). This cluster is the second least numerous (355 users, 18\%). 
Figure 1. Four clusters of Facebook link sharers. Link usage proportions depicted by box plot (left side) and independent variables statistics (right side)
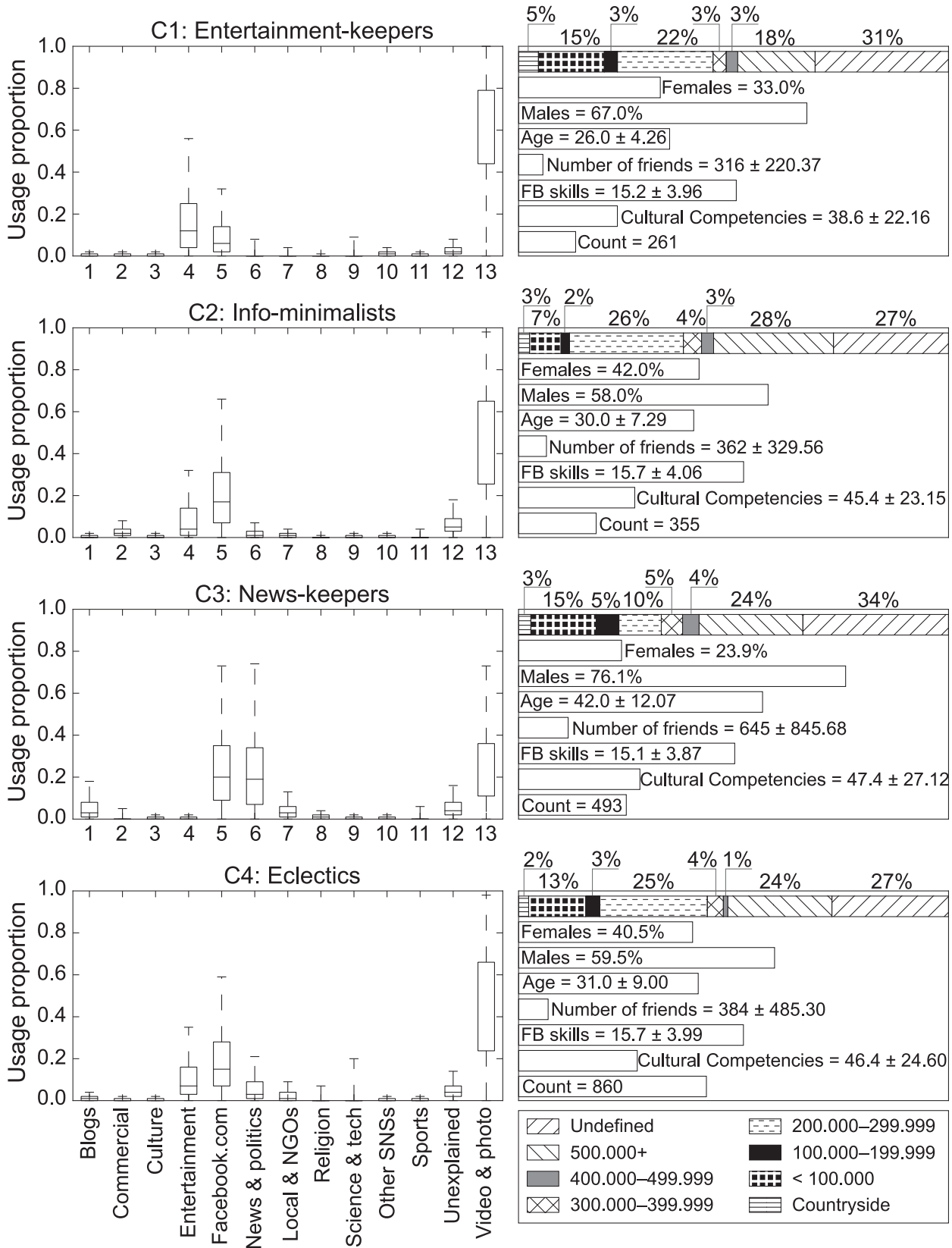

\begin{tabular}{|c|c|}
\hline $2 \% \quad 3 \% \quad 4 \%$ & \\
\hline $13 \% \quad 25 \%$ & $24 \%$ \\
\hline 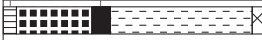 & \\
\hline Females $=40.5 \%$ & \\
\hline Males $=59.5 \%$ & \\
\hline Age $=31.0 \pm 9.00$ & \\
\hline Number of friends $=$ & $4 \pm 485.30$ \\
\hline FB skills $=15.7 \pm 3.99$ & \\
\hline Cultural C & opetencies $=46.4 \pm 24.60$ \\
\hline Count $=860$ & \\
\hline$\measuredangle \backslash$ Undefined & E- 200.000-299.999 \\
\hline$\triangle \nabla 500.000+$ & 100.000-199.999 \\
\hline 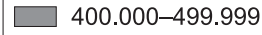 & $\boldsymbol{H} \boldsymbol{H}<100.000$ \\
\hline$\triangle$ 300.000-399.999 & $\equiv$ Countryside \\
\hline
\end{tabular}

Source: own elaboration.

There are 493 (25\%) News-keepers in the sample (see: cluster "C3"). These users are the primary providers of News links. Based on the above discussion it is safe to 
assume that high usage proportions of FB.com and Visual categories depict using these communication channels for spreading political messages. Also, in this context, the relatively high usage proportions for Blogs and Local categories are not surprising. News-keepers are also relatively moderate in terms of gatekeeping Visual links.

Gatekeeping strategy of Eclectics ("C4") is to provide a mixture of news and entertainment links. This is the most numerous cluster ( 860 observations - 43.6\%). It represents the most typical linking behavior. All four types of users can be ordered simultaneously by mean age and the usage proportion of politics-related links: Entertainment-keepers, Info-minimalists, Eclectics, and News-keepers. The older the users, the more politics-related links in the usage proportion. Thus, the Eclectics are the "middle class" of the distributed gatekeepers.

\section{RQ4: The determinants of receiving feedback}

In the context of sharing links on $\mathrm{FB}$, receiving feedback from other users may have a number of consequences. First of all, it may function as a means for receiving social acceptance/rejection of one's expressions of self, as the linking behavior is considered to serve the function of self-expression (Baek et al., 2011). Also, it functions as an input to Facebook's EdgeRank algorithm, which is responsible for filtering users' activities (Bucher, 2012). Thus, the received feedback impacts user's visibility in the social network.

Table 4 presents intercorrelation coefficients between six independent variables (variables 1 to 6), as well as the correlation coefficients between the independent variables and the average feedback per link (variable 7), and between the independent variables and the fractions of links in the respective categories (variables 8 to 20 ).

Age correlated weakly and positively with the amount of received feedback $(\mathrm{r}=.093, \mathrm{p}<.01)$. In other words, older users receive slightly more feedback than younger ones. This might seem surprising as younger users are often viewed as the primary gainers of the social media. Younger users, in fact, present slightly higher FB skills $(\mathrm{r}=-.126, \mathrm{p}<.01)$, but in the context of the received feedback per link posted they, apparently, are not privileged.

The correlation coefficient between gender and the average feedback per link shows that women receive less feedback than men $(r=-.124, \mathrm{p}<.01)$. It is important to notice, though, that women tend to have fewer friends than men $(r=-.165$, $\mathrm{p}<.01$ ), and the number of friends correlates positively with receiving feedback $(\mathrm{r}=.433, \mathrm{p}<.01)$. The location size correlated weakly and positively with the amount of received feedback $\left(\mathrm{r}_{\mathrm{s}}=.177, \mathrm{p}<.01\right)$.

Cultural competence correlated weakly with the amount of received feedback $(\mathrm{r}=.184, \mathrm{p}<.01)$. A possible explanation is that users with wider interests (i.e., more culturally competent users) are more likely to pick up and share interesting links, and thus gain more feedback. 
Table 4. Correlation matrix for user characteristics and the amount of received feedback

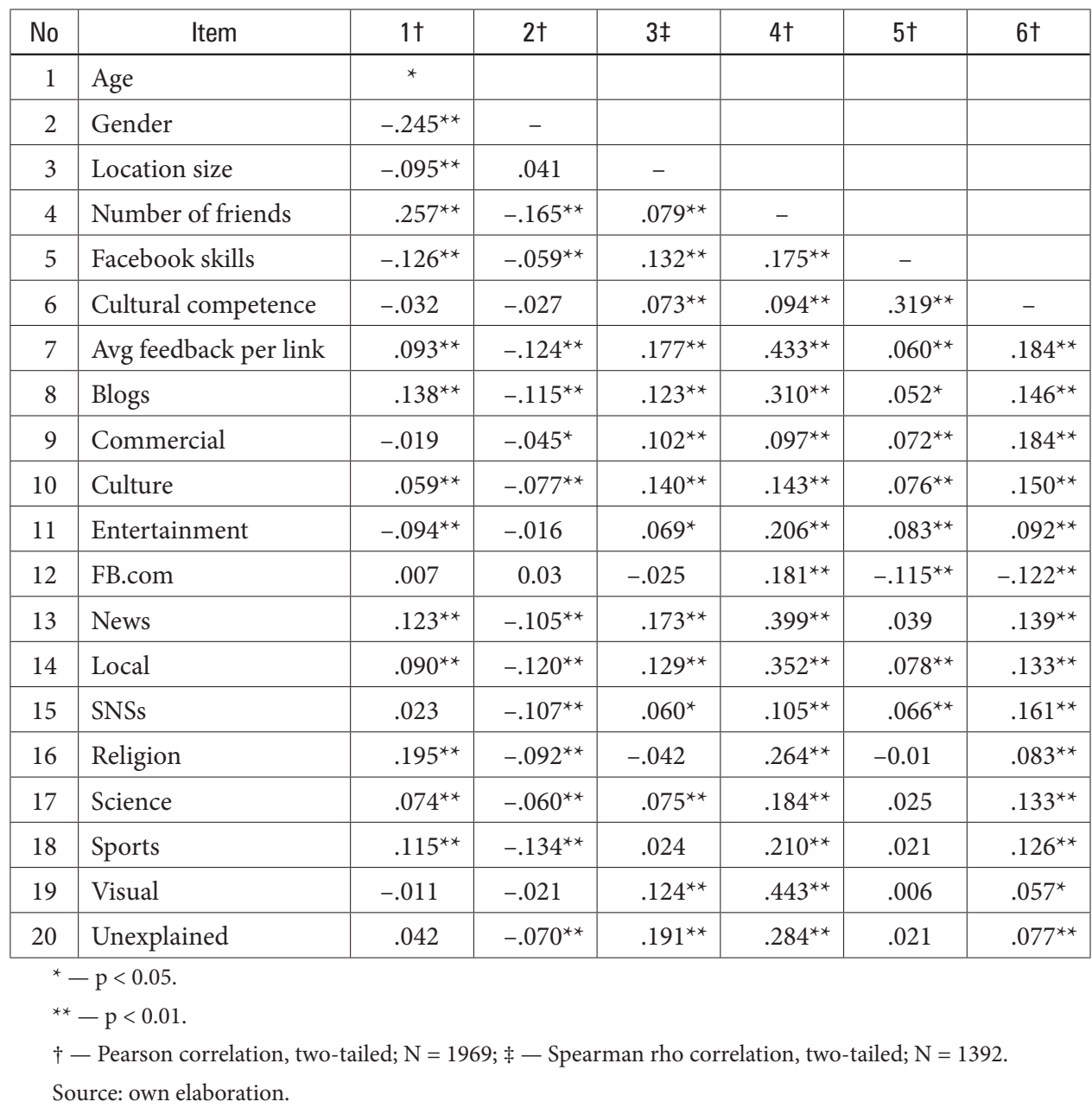

\section{RQ5: Receiving feedback and types of links}

The number of friends is the strongest predictor of the received feedback $(\mathrm{r}=.433, \mathrm{p}<.01)$, and it correlates with all of the discussed Web site categories. Age correlates weakly but positively with feedback for $B \operatorname{logs}(\mathrm{r}=.138, \mathrm{p}<.01)$ and News $(\mathrm{r}=.123, \mathrm{p}<.01)$. In other words, older users not only post more news-related links, but also receive more feedback for doing so. Interestingly, there is no reverse effect: younger users link more to Entertainment and Visual, but they do not receive more feedback in these categories $(\mathrm{r}=-.094, \mathrm{p}<.01$ and $\mathrm{r}=-.011$, N.S., respectively) than the older users do. Moreover, the older users tend to receive more feedback than the younger ones for Religion $(\mathrm{r}=.195, \mathrm{p}<.01)$ and Sports $(\mathrm{r}=.115, \mathrm{p}<.01)$ links.

Also, a number of weak correlations suggest that women receive less feedback than men for Blogs $(\mathrm{r}=-.115, \mathrm{p}<.01)$, News $(\mathrm{r}=-.105, \mathrm{p}<.01)$, Local $(\mathrm{r}=-.120$, 
$\mathrm{p}<.01)$, SNSs $(\mathrm{r}=-.107, \mathrm{p}<.01)$ and Sports $(\mathrm{r}=-.134, \mathrm{p}<.01)$. These findings suggest that the age/gender - gatekeeper/audience divides are socially established as older users and males receive more rewards for their gatekeeping efforts.

A similar pattern is also visible in the context of the location size. A number of weak correlations between the location size and the amount of received feedback appears for the following categories: Blogs $\left(\mathrm{r}_{\mathrm{s}}=.123, \mathrm{p}<.01\right)$, Commercial $\left(\mathrm{r}_{\mathrm{s}}=.102\right.$, $\mathrm{p}<.01)$, Culture $\left(\mathrm{r}_{\mathrm{s}}=.140, \mathrm{p}<.01\right)$, News $\left(\mathrm{r}_{\mathrm{s}}=.173, \mathrm{p}<.01\right)$, Local $\left(\mathrm{r}_{\mathrm{s}}=.129, \mathrm{p}<.01\right)$. This suggests that also the domination of larger cities inhabitants in disseminating the news is socially established.

\section{CONCLUSION}

In the present paper we studied link sharing practices of Facebook users. They differ widely in terms of link sharing behaviors: $20 \%$ of users under study shared $65 \%$ of the links. This kind of activity is a domain of the older and more culturally competent users. The younger ones tend to diversify their usage of the service and thus they concentrate on sharing links to a lesser extent. The more culturally competent users obtain the news from more varied sources, thanks to which they may more often have the chance to share interesting links with their friends.

Our research corresponds to a number of previous studies. We attempt to demonstrate that relatively few users are responsible for the majority of content distribution on Facebook, which supports the findings of Hargittai and Walejko (2008). In accordance with the findings of Glynn et al. (2012), we point out that young users and women are more likely to form an audience for Facebook news disseminators. Similarly to studies presented by Karahasanović et al. (2009), we show that older users, more often than younger ones, participate in SNSs to express themselves politically. Our results also support McAndrew and Jeong's (2012) findings about the negative relation between age posting links. Lee and Ma's (2012) findings about the split between news sharing and entertainment needs are also supported by our cluster analysis that led to the distinction of News-keeper and Entertainment-keeper types of linking behavior.

In accordance with the hypothesis by Holbert et al. (2010), social networking tools have enabled their users to participate in filtering political news, although this opportunity is exploited primarily by older male adults. Younger male users and female ones as well as individuals living in smaller locations play the role of the audience and the source of social feedback for the gatekeepers, at least for those who engage in spreading political news. In other words, although the gatekeeping power is distributed among millions of Facebook users, this distribution is not regular once the users' characteristics and types of links are taken into account.

It could be assumed that the agenda-setting of traditional media is mostly reproduced on FB in accordance with the socio-structural similarities (e.g. age, gender, location) between the characteristics of the distributed gatekeepers and the 
media officials. This article shows that although younger users employ a wider set of FB competencies, older ones are quite successful in using the set of options they are familiar with. Nevertheless, it is important to notice that this success, measured by social feedback received from other FB users, was observed here in the context of spreading politics, religion, and sports-related links.

In this context, it is important to outline the broader background of social networking services use in Poland. According to the data obtainable by means of the advertisements creation tool on Facebook (Facebook, 2014), in Poland in January 2014 there were 120,000 men at the age of $65+$ using the service, as compared to 80,000 women. In the remaining age categories, women account for the majority (i.e., for the age of 60-64 there were 72,000 men and 88,000 women).

In 2009 having an account on one of the social services and using it was declared by $68 \%$ of Internet users ( $40 \%$ of the total population of Poland), with $35 \%$ having an account on the Polish service - NK.pl, $20 \%$ on FB, and $13 \%$ on a different one. In April 2011, already 57.5\% of Internet users had an account on NK.pl, 34\% on FB, and $22 \%$ had an account on a different social service (Batorski, 2011). However, during the following two years NK.pl lost 10\% of its scope, and Facebook gained almost 15\%. Nevertheless, what is most interesting for us is the fact that in 2010 and 2011 men withdrew from NK.pl more rapidly than women (WirtualneMedia.pl, 2013). The first mass social service in Poland, Nasza-klasa.pl, has been successful due to the pressure to look for and link to people from the same schools - old time boyfriends and girlfriends from the same school years. Women, especially older ones, have remained loyal to the NK.pl service more often than men, hence there are fewer of them on FB.

The quantitative dominance of men at the age of $65+$ among FB users may also be connected with the fact that they had access to new technologies at the time when they first appeared in Poland and still were very poorly popularized, basically being available only in the workplace (it is assumed that in Poland the rise of the Internet is the year 1991). This opportunity was primarily used by educated men (academic circles, business circles, higher level officers), who could familiarize themselves with the Internet during their professional activity period. In this context, what was crucial was the required by law, mandatory retirement of women at the age of 60 whereas the retirement age for men was 65 . This caused the situation that in the group of the oldest users there are fewer women, since in previous years they had a lower chance of acquiring Internet skills, and there are more men possessing high cultural and social capital.

\section{REFERENCES}

Baek, K., Holton, A., Harp, D., Yaschur, C. (2011). The links that bind: Uncovering novel motivations for linking on Facebook. Computers in Human Behavior, 27 (6), pp. 2243-2248.

Baresch, B., Knight, L., Harp, D., Yaschur, C. (2011). Friends who choose your news: An analysis of content links on Facebook. ISOJ: The Official Research Journal of International Symposium on 
Online Journalism, Austin, TX, 1 (2). Retrieved November 30, 2013 from http://online.journalism.utexas.edu/ 2011/papers/Baresch2011.pdf.

Batorski, D. (2011). Use of information and communication technologies. Contemporary Economics, 5 (3), pp. 233-234.

Bernstein, M.S., Bakshy, E., Burke, M., Karrer, B. (2013). Quantifying the invisible audience in social networks. In: ACM SIGCHI Conference on Human Factors in Computing Systems.

Bozdag, V.E. (2015). Bursting the Filter Bubble: Democracy, Design, and Ethics (Doctoral dissertation, TU Delft, Delft University of Technology).

Brandtzæg, P.B., Lüders, M., Skjetne, J.H. (2010). Too many Facebook "friends"? Content sharing and sociability versus the need for privacy in social network sites. International Journal of Human-Computer Interaction, 26 (11), pp. 1006-1030.

Bruns, A. (2003). Gatewatching, not gatekeeping: Collaborative online news. Media International Australia Incorporating Culture and Policy. Quarterly Journal of Media Research and Resources, 107, pp. 31-44.

Bucher, T. (2012). Want to be on the top? Algorithmic power and the threat of invisibility on Facebook. New Media \& Society, 14 (7), pp. 1164-1180.

Democracy UK. (2010). A snapshot of Facebook in 2010. Retrieved November 25, 2013 from https:// www.facebook.com/notes/democracy-uk-on-facebook/a-snapshot-of-facebook-in-2010/ 172769082761603.

Diaz, A. (2008). Through the Google goggles: Sociopolitical bias in search engine design. In: Spink, A., Zimmer, M. (eds.). Web Search: Multidisciplinary Perspectives. Berlin: Springer-Verlag, pp. 11-34.

Diddi, A., LaRose, R. (2006). Getting hooked on news: Uses and gratifications and the formation of news habits among college students in an internet environment. Journal of Broadcasting \& Electronic Media, 50 (2), pp. 193-210.

Dunne, Á., Lawlor, M.A., Rowley, J. (2010). Young people's use of online social networking sites a uses and gratifications perspective. Journal of Research in Interactive Marketing, 4 (1), pp. $46-$ 58.

Ellison, N.B., Boyd, D.M. (2007). Social network sites: Definition, history, and scholarship. Journal of Computer-Mediated Communication, 13 (1), pp. 210-230.

Facebook.com. (2014). Create Ad. Available at: https://www.facebook.com/ads/create/.

Glynn, C.J., Huge, M.E., Hoffman, L.H. (2012). All the news that's fit to post: A profile of news use on social networking sites. Computers in Human Behavior, 28 (1), pp. 113-119.

Hargittai, E., Walejko, G. (2008). The participation divide: Content creation and sharing in the digital age. Information, Communication and Society, 11 (2), pp. 239-256.

Holbert, R.L., Garrett, R.K., Gleason, L.S. (2010). A new era of minimal effects? A response to Bennett and Iyengar. Journal of Communication, 60 (1), pp. 15-34.

Karahasanović, A., Brandtzæg, P.B., Heim, J., Lüders, M., Vermeir, L., Pierson, J., Lievens, B., Vanattenhoven, J., Jans, G. (2009). Co-creation and user-generated content - elderly people's user requirements. Computers in Human Behavior, 25 (3), pp. 655-678.

Lee, C.S., Ma, L. (2012). News sharing in social media: The effect of gratifications and prior experience. Computers in Human Behavior, 28 (2), pp. 331-339.

McAndrew, F.T., Jeong, H.S. (2012). Who does what on Facebook? Age, sex, and relationship status as predictors of Facebook use. Computers in Human Behavior, 28 (6), pp. 2359-2365.

Nadkarni, A., Hofmann, S.G. (2012). Why do people use Facebook? Personality and Individual Differences, 52, pp. 243-249.

Pariser, E. (2011). The Filter Bubble: What the Internet is Hiding from You. New York: Penguin UK.

Robertson, S.P., Vatrapu, R.K., Medina, R. (2009, May). The social life of social networks: Facebook linkage patterns in the 2008 US presidential election. In: Proceedings of the 10th Annual International Conference on Digital Government Research: Social Networks: Making Connections between Citizens, Data and Government. Digital Government Society of North America, pp. 6-15. 
Rogers, R. (2009). The Googlization question, and the inculpable engine. In: Becker, K., Stalder, F. (eds.). Deep Search: The Politics of Search Engines Beyond Google. Innsbruck: Studien Verlag, pp. 173-184.

Rubin, A.M. (1984). Ritualized and instrumental television viewing. Journal of Communication, 34 (3), pp. 67-77.

Ruggiero, T.E. (2000). Uses and gratifications theory in the 21st century. Mass Communication \& Society, 3 (1), pp. 3-37.

Schiffer, A. (2007, August). Between pajamas and Pulitzers: Distributed gatekeeping and the potential of blogs as news media. In: Conference Papers - American Political Science Association, pp. 1-40.

Shoemaker, P.J., Reese, S.D. (1996). Mediating the Message. White Plains, NY: Longman.

Smith, B. (2012). One chart that explains the transformation of media in 2012. BuzzFeed, published July 18, 2012. Retrieved November 25, 2013 from http://www.buzzfeed.com/bensmith/onechart-that-explains-the-transformation-of-medi.

Stefanone, M.A., Lackaff, D. (2009). Reality television as a model for online behavior: Blogging, photo, and video sharing. Journal of Computer-Mediated Communication, 14 (4), pp. 964-987.

Valenzuela, S., Park, N., Kee, K.F. (2009). Is there social capital in a social network site?: Facebook use and college students' life satisfaction, trust, and participation. Journal of Computer-Mediated Communication, 14 (4), pp. 875-901.

Webster, J.G., Ksiazek, T.B. (2012). The dynamics of audience fragmentation: Public attention in an age of digital media. Journal of Communication, 62 (1), pp. 39-56.

WirtualneMedia.pl. (2013). Facebook zyskuje na wsi, NK.pl traci „białych kotnierzyków” - raport o social media $w$ Polsce [Facebook gains users in the countrywide, NK.pl loses white collars a report on social media in Poland]. WirtualneMedia.pl, published June 11, 2012. Retrieved November 25, 2013 from http://www.wirtualnemedia.pl/artykul/ facebook-zyskuje-na-wsi-nkpl-traci-bialych-kolnierzykow-raport-o-social-media-w-polsce. 